\title{
BMJ
}

\section{Migraine with aura and risk of cardiovascular and all cause mortality in men and women: prospective cohort study}

\author{
Larus S Gudmundsson, doctoral student, ${ }^{1}$ Ann I Scher, associate professor, ${ }^{2}$ Thor Aspelund, associate \\ professor, ${ }^{3,4}$ Jon H Eliasson, neurologist, ${ }^{5}$ Magnus Johannsson, professor, ${ }^{1}$ Gudmundur Thorgeirsson, \\ professor, ${ }^{4,6}$ Lenore Launer, senior investigator, ${ }^{7}$ Vilmundur Gudnason, professor ${ }^{3,4}$
}

${ }^{1}$ Department of Pharmacology and Toxicology, University of Iceland Hagi Hofsvallagata 53, IS-107 Reykjavik, Iceland

${ }^{2}$ Department of Preventive Medicine and Biometrics,

Uniformed Services University, Bethesda, MD, USA

${ }^{3}$ Icelandic Heart Association, Holtasmara 1, IS-201 Kopavogur, Iceland

${ }^{4}$ University of Iceland, Reykjavik, Iceland

${ }^{5}$ Reykjalundur Rehabilitation Centre, Mosfellsbær, Iceland

${ }^{6}$ Landspitali University Hospital, Reykjavik, Iceland

${ }^{7}$ Laboratory of Epidemiology, Demography, and Biometry, National Institute on Aging,

Bethesda, MD, USA

Correspondence to: $\mathrm{LS}$

Gudmundsson Isg@hi.is, V

Gudnason v.gudnason@hjarta.is

Cite this as: BMJ 2010;341:C3966 doi:10.1136/bmi.c3966

\section{ABSTRACT}

Objective To estimate whether migraine in mid-life is associated with mortality from cardiovascular disease, other causes, and all causes.

Design Population based cohort study.

Setting Reykjavik, Iceland.

Participants 18725 men and women, born 1907-35 and living in Reykjavik and adjacent communities.

Main outcome measures Mortality from cardiovascular disease, non-cardiovascular disease, and all causes. Questionnaires and clinical measures were obtained in mid-life (mean age 53, range 33-81) in the Reykjavik Study (1967-91). Headache was classified as migraine without aura, migraine with aura, or non-migraine headache. Median follow-up was 25.9 years (0.1-40. 2 years), with 470990 person years and 10358 deaths: 4323 from cardiovascular disease and 6035 from other causes. We used Cox regression to estimate risk of death in those with migraine compared with others, after adjusting for baseline risk factors.

Results People with migraine with aura were at increased risk of all cause mortality (adjusted (for sex and multivariables) hazard ratio $1.21,95 \%$ confidence interval 1.12 to 1.30 ) and mortality from cardiovascular disease $(1.27,1.13$ to 1.43$)$ compared with people with no headache, while those with migraine without aura and non-migraine headache were not. Further examination of mortality from cardiovascular disease shows that people with migraine with aura were at increased risk of mortality from coronary heart disease $(1.28,1.11$ to 1.49$)$ and stroke $(1.40,1.10$ to 1.78$)$. Women with migraine with aura were also at increased risk of mortality from noncardiovascular disease $(1.19,1.06$ to 1.35$)$.

Conclusions Migraine with aura is an independent risk factor for cardiovascular and all cause mortality in men and women. The risk of mortality from coronary heart disease and stroke mortality is modestly increased in people with migraine, particularly those with aura.

\section{INTRODUCTION}

In recent years, numerous studies have suggested that migraine, particularly migraine with aura, is a risk factor for clinical and subclinical cardiovascular disease. ${ }^{1-6}$ Both we and others have examined the relation between cardiovascular risk factors and migraine, showing differences in risk factors between those with and without migraine. ${ }^{7-10}$ Less well understood is the degree, if any, to which migraine is related to the risk of all cause or cardiovascular mortality. Few articles have been published on migraine and cardiovascular disease or overall mortality, with somewhat conflicting findings, depicting migraine as a risk factor, neutral, or a protective factor. ${ }^{411-14}$ Because of insufficient data, a recent meta-analysis could draw no conclusions regarding the risk of mortality associated with migraine with aura. ${ }^{6} \mathrm{We}$ estimated the risk of mortality from cardiovascular disease, non-cardiovascular disease, and all causes associated with having migraine with or without aura at mid-life during up to four decades of follow-up in a population based cohort.

\section{METHODS}

Study design

Detailed descriptions of the Reykjavik Study have previously been published. ${ }^{1516}$ In brief, the Reykjavik Study is a population based cohort study established in 1967 by the Icelandic Heart Association to prospectively study cardiovascular disease in Iceland. ${ }^{16}$ The cohort included a random sample of men and women born in 1907-35 and living in Reykjavik. The first examination of each person occurred between 1967 and 1991, the average year of examination was 1975 (see appendix 1 on bmj.com).

Headache assessment

Participants were asked about current headache symptoms. ${ }^{8}$ Those reporting headache once or more a month were asked whether the headaches were accompanied by any of the following five features of migraine: nausea or vomiting, unilateral location, photophobia, visual disturbance during or preceding headache, and unilateral numbness preceding headache.

We classified participants into four mutually exclusive categories of headache: no headache once or more a month (reference category), non-migraine headache, migraine without aura, and migraine with aura. The category of migraine without aura included individuals with headache with at least two of the three non-aura 
symptoms (nausea, unilateral location, photophobia). The category of migraine with aura included those who reported visual aura or sensory aura, or both. Individuals with headache but no non-aura symptoms or only one non-aura symptom were defined as having non-migraine headache. Aura symptoms took precedence over other symptoms. The classification scheme represents an approximation of the 2004 diagnostic criteria of the International Headache Society (IHS) ${ }^{17}$ for migraine with or without aura, which were formalised after the Reykjavik Study data were collected. Features for migraine without aura that are missing from these IHS criteria include pulsatility, exacerbation with activity, and phonophobia. Criteria for migraine with aura missing from these criteria include duration of aura (aura symptoms must last between 5 and 60 minutes) and speed of onset (aura symptoms must develop gradually over more than 5 minutes).

\section{Assessment of demographic and cardiovascular factors}

Assessment of cardiovascular risk was performed at the same time as the migraine assessment. Nurses administered questionnaires, made physical measurements, performed spirometry and electrocardiography, and collected venous blood samples.

\section{Endpoint definition}

After entering the study, participants were followed for up to 40 years (until the end of 2007). Statistics relating to the cause of death, given by an ICD (international classification of disease) code, were obtained from Statistics Iceland. The main end points in our study were deaths from cardiovascular disease, non-cardiovascular disease, and all causes. We also defined three additional cardiovascular end points: fatal coronary heart disease, fatal stroke, and other fatal cardiovascular disease (such as non-coronary heart disease and non-stroke), based on diagnostic codes as defined in the SCORE project (systematic coronary risk evaluation project). ${ }^{18}$ In the current study we split mortality from non-coronary atherosclerotic cardiovascular disease (non-coronary heart disease-cardiovascular disease) into mortality from stroke and other cardiovascular disease. An end point for fatal coronary heart disease was obtained from hospital records, which were systematically reviewed according to the monitoring of trends and determinants in cardiovascular disease (MONICA) protocol. ${ }^{19}$

For stroke mortality we used ICD-9 (ninth revision) codes 431, 433, 434, 436, and 438 and ICD-10 (10th revision) codes I61, I63, I64, I66, and I69.

At the start of the study, there were 18903 participants, of whom $68(0.36 \%)$ were lost to follow-up for cause specific mortality and $110(0.58 \%)$ had missing data on blood pressure, cholesterol concentration, or body mass index (BMI) and were omitted. This left a sample of 18725 (99\%), with 470990 years of followup during which 10358 participants died. For cause specific mortality, 4323 died from cardiovascular disease and 6035 from non-cardiovascular disease. The 4323 deaths from cardiovascular disease consisted of 2810 deaths from coronary heart disease, 927 from stroke, and 586 from other forms of cardiovascular disease.

\section{Statistical analysis}

We used Cox proportional hazards to estimate the relative risk of death (hazard ratio) after adjusting for demographic and baseline risk factors for cardiovascular disease. Significance testing was two sided and based on a 5\% probability level. Risk factors for mortality were entered into the Cox model in a stepwise manner, including those with $\mathrm{P}$ values under 0.2 for multivariable adjustment. For all cause mortality, we adjusted for age, BMI, education (primary, secondary, junior college, or university), smoking (none, current, previous), and systolic and diastolic blood pressure. For mortality from cardiovascular disease we additionally adjusted for current diabetes mellitus, cholesterol concentration, self reported history of coronary event, self reported current use of antihypertensive drugs, and use of oral contraceptives in women.

We tested the Cox models for possible violations of the proportional hazards assumption. ${ }^{2021}$ The assumption was not violated except for men with migraine without aura when death from coronary heart disease was the end point. When participants were censored after 30 years of follow-up, the proportional hazards assumption held. This resulted in somewhat lower hazard ratio for all three categories of headache compared with when the follow-up was up to 40 years. We also used a $\log -\log$ plot. The curves for the groups in the current study were roughly parallel, indicating no violation of the proportionality of the hazards assumption.

We also estimated median life expectancy at age 50 by headache status from a Cox model adjusted for age. Men and women were compared descriptively with respect to headache/migraine status and mortality from cardiovascular disease through Nelson-Aalen cumulative hazard curves. ${ }^{2223}$ We estimated the absolute 10 year risk of mortality from all causes and cardiovascular disease by sex and headache status from the Cox model at ages 50,60, and 70. The software package used was Stata version 9 (StataCorp LP, College Station, TX, USA) and SAS/STAT software version 9.2.

\section{RESULTS}

Table 1 shows the characteristics of the study participants. There were 9044 men and 9681 women, with an average age of 52.8 (range 33-81) at study entry. Overall, $11 \%(2023)$ of the participants $(6 \%(571)$ of men, $15 \%$ (1452) of women) were classified as having migraine, including 3\% with migraine without aura (1\% (128) of men, $5 \%(498)$ of women) and $8 \%$ with migraine with aura $(5 \%$ (443) of men, 10\% (954) of women). Among participants with aura, the proportion with visual aura, sensory aura, and both visual and sensory aura was $72 \%, 17 \%$, and $11 \%$ for men and $65 \%, 17 \%$, and $19 \%$ for women, respectively. Within the migraine with aura group, 81\% (358) of the men and $89 \%$ (849) of the women reported having at least one other migraine symptom. 


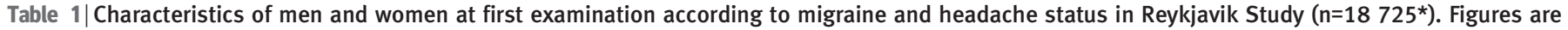
percentages of participants unless stated otherwise

\begin{tabular}{|c|c|c|c|c|c|c|c|c|c|c|}
\hline \multirow[b]{2}{*}{ Characteristic } & \multicolumn{5}{|c|}{ Men } & \multicolumn{5}{|c|}{ Women } \\
\hline & $\begin{array}{c}\text { No } \\
\text { headache }\end{array}$ & $\begin{array}{c}\text { Non- } \\
\text { migraine } \\
\text { headache } \dagger\end{array}$ & Migraine & $\begin{array}{c}\text { Migraine } \\
\text { without } \\
\text { auraf }\end{array}$ & $\begin{array}{l}\text { Migraine } \\
\text { with aura§ }\end{array}$ & $\begin{array}{c}\text { No } \\
\text { headache }\end{array}$ & $\begin{array}{c}\text { Non- } \\
\text { migraine } \\
\text { headache }\end{array}$ & Migraine & $\begin{array}{c}\text { Migraine } \\
\text { without } \\
\text { auraf }\end{array}$ & $\begin{array}{c}\text { Migraine } \\
\text { with aura§ }\end{array}$ \\
\hline Mean (SD) age (years) & $52.7(8.6)$ & $51.5(8.7)$ & $50.6(8.2)$ & $49.9(7.3)$ & $50.8(8.4)$ & $54.4(9.0)$ & $52.1(9.0)$ & $50.7(8.4)$ & $49.9(8.1)$ & $51.1(8.6)$ \\
\hline Mean (SD) BMI & $25.8(3.4)$ & $25.9(3.5)$ & $25.6(3.3)$ & $25.6(3.2)$ & $25.6(3.3)$ & $25.2(4.2)$ & $25.1(4.4)$ & $24.8(4.2)$ & $24.7(4.0)$ & $24.9(4.3)$ \\
\hline $\begin{array}{l}\text { Mean (SD) cholesterol } \\
(\mathrm{mmol} / \mathrm{l})\end{array}$ & $6.4(1.1)$ & $6.3(1.0)$ & $6.4(1.1)$ & $6.2(1.1)$ & $6.4(1.1)$ & $6.6(1.3)$ & $6.6(1.2)$ & $6.5(1.2)$ & $6.4(1.2)$ & $6.6(1.2)$ \\
\hline $\begin{array}{l}\text { Mean (SD) systolic blood } \\
\text { pressure }(\mathrm{mm} \mathrm{Hg})\end{array}$ & $141.1(21.1)$ & $139.9(21.6)$ & $137.9(20.6)$ & $139.3(22.5)$ & $137.5(20.1)$ & $136.8(22.5)$ & $135.7(21.8)$ & $133.7(20.7)$ & $132.3(19.4)$ & $134.5(21.3)$ \\
\hline $\begin{array}{l}\text { Mean }(\mathrm{SD}) \text { diastolic blood } \\
\text { pressure }(\mathrm{mm} \mathrm{Hg})\end{array}$ & $89.3(11.2)$ & $90.2(12.3)$ & $88.8(11.4)$ & $90.6(12.4)$ & $88.3(11.1)$ & $84.1(11.3)$ & $84.3(11.3)$ & $84.1(11.4)$ & $83.3(11.1)$ & $84.5(11.5)$ \\
\hline Pulse pressure $(\mathrm{mm} \mathrm{Hg})$ & $51.9(15.0)$ & $49.8(14.2)$ & $49.1(13.8)$ & $48.8(13.8)$ & $49.2(13.8)$ & $52.7(16.1)$ & $51.5(15.5)$ & $49.7(14.5)$ & $49.0(13.1)$ & $50.0(15.2)$ \\
\hline No of participants & 7068 & 1405 & 571 & 128 & 443 & 6003 & 2226 & 1452 & 498 & 954 \\
\hline Headache & NA & 100 & 100 & 100 & 100 & NA & 100 & 100 & 100 & 100 \\
\hline Pain, unilateral & NA & 30 & 58 & 81 & 51 & NA & 27 & 67 & 80 & 60 \\
\hline Nausea/vomiting & NA & 4 & 37 & 66 & 28 & NA & 9 & 62 & 80 & 53 \\
\hline Photophobia & NA & 7 & 46 & 68 & 40 & NA & 7 & 59 & 65 & 56 \\
\hline Visual symptoms & NA & NA & 64 & NA & 82 & NA & NA & 55 & NA & 84 \\
\hline Sensory symptoms & NA & NA & 22 & NA & 28 & NA & NA & 23 & NA & 35 \\
\hline $\begin{array}{l}\text { Elementary or less } \\
\text { education }\end{array}$ & 33 & 36 & 38 & 33 & 39 & 55 & 54 & 55 & 50 & 57 \\
\hline Hypertension treatment & 7 & 8 & 8 & 9 & 8 & 11 & 12 & 10 & 8 & 11 \\
\hline Current smoking & 55 & 56 & 56 & 52 & 58 & 41 & 40 & 40 & 36 & 42 \\
\hline Former smoking & 23 & 24 & 24 & 25 & 23 & 15 & 15 & 16 & 18 & 16 \\
\hline Medical hormone use & 0.3 & 0.4 & 1 & 1 & 1 & 5 & 7 & 9 & 8 & 9 \\
\hline Oral contraceptive use & NA & NA & NA & NA & NA & 3 & 5 & 6 & 6 & 5 \\
\hline Diabetes & 4 & 5 & 4 & 6 & 4 & 3 & 3 & 3 & 2 & 4 \\
\hline History of coronary event & 3 & 2 & 1 & 0 & 1 & 1 & 0.4 & 0.4 & 0.4 & 0.4 \\
\hline
\end{tabular}

$\mathrm{NA}=$ not applicable.

*Of original 18903 participants, $68(0.36 \%)$ were lost to follow-up and $110(0.58 \%)$ had missing data on blood pressure, cholesterol concentration, or BMI.

†Headache without or with one symptom of migraine once or more a month.

$\ddagger 2-3$ of unilateral, photophobia, nausea symptoms.

§Migraine with visual or sensory symptoms, or both. Participants with symptoms of migraine without aura and migraine with aura were classified as migraine with aura.

IMyocardial infarction, angioplasty, or coronary artery bypass graft.

Participants with migraine and headache were significantly younger than those without headache. Systolic blood pressure was lower among men with migraine than among men without headache (adjusted for age and use of antihypertensive drugs). Pulse pressure was lower among men and women with migraine than those without headache and lower among men with non-migraine headache than those without headache (table 1). Compared with those without headache, people with migraine or with migraine with aura had less education and were more likely to be taking antihypertensive drugs or hormone treatment, or both.

\section{Migraine and non-migraine headache}

Compared with people with no headache, those with migraine were at significantly increased risk of mortality from all causes (hazard ratio 1.15, 95\% confidence interval 1.08 to $1.23, \mathrm{P}<0.001$, table 2 ) and from cardiovascular disease $(1.22,1.10$ to $1.36, \mathrm{P}<0.001$, table 3$)$. The risk was similar with and without adjustment for risk factors for cardiovascular disease. In models stratified by sex, men and women with migraine were at similarly increased risk of all cause mortality $(\mathrm{P}=0.87$ for interaction by sex $)$, but for mortality from cardiovascular disease men were at marginally higher risk than women $(\mathrm{P}=0.057$ for interaction by sex). Women, but not men, with non-migraine headache were also at increased risk of mortality from cardiovascular disease. The above results were similar when we excluded the 266 people with a history of coronary artery disease from the model. Table 4 shows results for mortality from non-cardiovascular cause.

When we divided cardiovascular disease mortality into deaths from coronary heart disease, stroke, or other cardiovascular disease, people with migraine were at increased risk of death from coronary heart disease (sex and multivariable adjusted hazard ratio $1.22,1.07$ to $1.39, \mathrm{P}=0.003$, table 5$)$ and stroke (1.30, 1.05 to $1.61, \mathrm{P}=0.017$, table 6 ). Risk of death from coronary heart disease and stroke, however, was significant only for men with migraine in the sex stratified models. Men and women with migraine were not at increased risk of mortality from other cardiovascular diseases (table 7). 
Table 2|Age and multivariable* adjusted hazard ratios ( $95 \%$ confidence intervals) for mortality from all cause according to migraine status in men and women in Reykjavik Study ( $n=18$ 725†)

\begin{tabular}{|c|c|c|c|c|c|}
\hline & No headache & Non-migraine headache $\ddagger$ & Migraine & Migraine without aura§ & Migraine with auraf \\
\hline \multicolumn{6}{|l|}{ Men } \\
\hline Died/total & $4519 / 7068$ & $845 / 1405$ & $364 / 571$ & $73 / 128$ & $291 / 443$ \\
\hline Age adjusted & 1.00 & 0.99 (0.92 to 1.07$)$ & $1.12(1.01 \text { to } 1.25)^{\star \star}$ & $0.92(0.73$ to 1.17$)$ & $1.19(1.05 \text { to } 1.36)^{\star \star}$ \\
\hline Multivariable adjusted & 1.00 & 0.99 (0.92 to 1.06$)$ & $1.16(1.04 \text { to } 1.29)^{\star \star}$ & $0.95(0.76$ to 1.20$)$ & $1.23(1.09 \text { to } 1.38)^{\star \star}$ \\
\hline \multicolumn{6}{|l|}{ Women } \\
\hline Died/total & $2958 / 6003$ & $1008 / 2226$ & $664 / 1452$ & $198 / 498$ & $466 / 954$ \\
\hline Age adjusted & 1.00 & $1.02(0.95$ to 1.10$)$ & $1.12(1.03 \text { to } 1.22)^{\star \star}$ & $1.00(0.86$ to 1.15$)$ & $1.18(1.07 \text { to } 1.31)^{\star \star}$ \\
\hline Multivariable adjusted & 1.00 & 1.04 (0.97 to 1.12$)$ & $1.16(1.07 \text { to } 1.26)^{\star \star}$ & 1.06 (0.92 to 1.22$)$ & $1.21(1.09 \text { to } 1.33)^{\star \star}$ \\
\hline \multicolumn{6}{|l|}{ Men and women } \\
\hline Died/total & $7477 / 13071$ & $1853 / 3631$ & $1028 / 2023$ & $271 / 626$ & $757 / 1397$ \\
\hline Age-sex adjusted & 1.00 & 1.01 (0.96 to 1.06$)$ & $1.12(1.05 \text { to } 1.19)^{\star \star}$ & 0.97 (0.86 to 1.09$)$ & $1.18(1.10 \text { to } 1.27)^{\star \star}$ \\
\hline Multivariable adjusted & 1.00 & 1.01 (0.96 to 1.07$)$ & $1.15(1.08 \text { to } 1.23)^{\star \star}$ & $1.02(0.91$ to 1.16$)$ & $1.21(1.12 \text { to } 1.30)^{\star *}$ \\
\hline \multicolumn{6}{|c|}{ 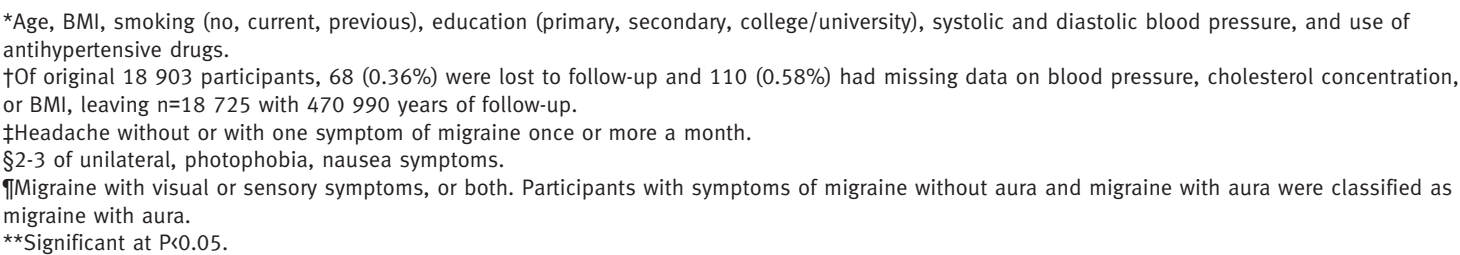 } \\
\hline
\end{tabular}

\section{Migraine with aura and without aura}

Among people with migraine, those with migraine with aura were at increased risk of mortality from all causes and cardiovascular disease (tables 2 and 3), but no increased risk was seen in those with migraine without aura. We studied the long term effects of migraine on mortality from cardiovascular disease using cumulative hazard curves. Men with migraine with aura were at marginally higher risk than women with migraine with aura (figure); this is also reflected in table 3 , but this difference was marginally significant $(\mathrm{P}=0.053$ for interaction by $\mathrm{sex})$. Women with migraine with aura were still at marginally significantly increased risk of cardiovascular disease mortality compared with women with no headache $(1.18,1.00$ to 1.40, $\mathrm{P}=0.053$, table 3 ).

The increased risk of mortality from cardiovascular disease in people with migraine with aura was higher among men than women for coronary heart disease and stroke, although not significantly; hazard ratios were 1.43 in men versus 1.17 in women for mortality from coronary heart disease (table 5) and 1.76 in men versus 1.26 in women for mortality from stroke (table 6 ) $(\mathrm{P}=0.12$ and 0.15 for interaction by sex for coronary heart disease and stroke mortality). To investigate this finding further, we divided non-cardiovascular disease

Table $3 \mid$ Age and multivariable* adjusted hazard ratios ( $95 \%$ confidence intervals) for mortality from cardiovascular disease according to migraine status in men and women in Reykjavik Study ( $\mathrm{n}=18 \mathrm{725} \dagger$ )

\begin{tabular}{|c|c|c|c|c|c|}
\hline & No headache & Non-migraine headache $\ddagger$ & Migraine & Migraine without aura§ & Migraine with auraף \\
\hline \multicolumn{6}{|l|}{ Men } \\
\hline Died/total & $2086 / 7068$ & $388 / 1405$ & $189 / 571$ & $38 / 128$ & $151 / 443$ \\
\hline Age adjusted & 1.00 & 0.99 (0.89 to 1.10$)$ & $1.28(1.11 \text { to } 1.49)^{\star \star}$ & 1.07 (0.78 to 1.48$)$ & $1.35(1.15 \text { to } 1.60)^{\star \star}$ \\
\hline Multivariable adjusted & 1.00 & 0.97 (0.87 to 1.08$)$ & $1.35(1.17 \text { to } 1.57)^{\star \star}$ & $1.14(0.83$ to 1.57$)$ & $1.42(1.20 \text { to } 1.68)^{\star *}$ \\
\hline \multicolumn{6}{|l|}{ Women } \\
\hline Died/total & $1061 / 6003$ & $377 / 2226$ & $222 / 1452$ & $66 / 498$ & $156 / 954$ \\
\hline Age adjusted & 1.00 & 1.12 (1.00 to 1.26$)$ & 1.15 (0.99 to 1.33$)$ & $1.04(0.81$ to 1.34$)$ & $1.20(1.01 \text { to } 1.42)^{\star \star}$ \\
\hline Multivariable adjusted & 1.00 & $1.13(1.01 \text { to } 1.27)^{\star \star}$ & $1.16(1.00$ to 1.34$)$ & $1.09(0.85$ to 1.40$)$ & 1.18 (1.00 to 1.40$)$ \\
\hline \multicolumn{6}{|l|}{ Men and women } \\
\hline Died/total & $3147 / 13071$ & $765 / 3631$ & $411 / 2023$ & $104 / 626$ & $307 / 1397$ \\
\hline Age-sex adjusted & 1.00 & 1.04 (0.96 to 1.13$)$ & $1.19(1.07 \text { to } 1.32)^{\star \star}$ & $1.02(0.84$ to 1.24$)$ & $1.25(1.11 \text { to } 1.41)^{\star \star}$ \\
\hline Multivariable adjusted & 1.00 & 1.04 (0.96 to 1.13$)$ & $1.22(1.10 \text { to } 1.36)^{\star \star}$ & $1.10(0.91$ to 1.34$)$ & $1.27(1.13 \text { to } 1.43)^{\star *}$ \\
\hline \multicolumn{6}{|c|}{$\begin{array}{l}\text { *Age, BMI, smoking (no, current, previous), education (primary, secondary, college/university), systolic and diastolic blood pressure, use of } \\
\text { antihypertensive drugs, cholesterol concentration, diabetes, history of coronary artery disease, and birth control use for women. } \\
\text { †Of original } 18903 \text { participants, } 68(0.36 \%) \text { were lost to follow-up and } 110(0.58 \%) \text { had missing data on blood pressure, cholesterol concentration, } \\
\text { or BMI, leaving } n=18725 \text { with } 470990 \text { years of follow-up. } \\
\text { †Headache without or with one symptom of migraine once or more a month. } \\
\S 2-3 \text { of unilateral, photophobia, nausea symptoms. } \\
\text { †Migraine with visual or sensory symptoms, or both. Participants with symptoms of migraine without aura and migraine with aura were classified as } \\
\text { migraine with aura. }\end{array}$} \\
\hline
\end{tabular}


Table $4 \mid$ Age and multivariable* adjusted hazard ratios (95\% confidence intervals) for mortality from non-cardiovascular disease (mortality from causes other than cardiovascular disease) according to migraine status in men and women in Reykjavik Study ( $\mathrm{n}=18 \mathrm{725} \dagger)$

\begin{tabular}{|c|c|c|c|c|c|}
\hline & No headache & Non-migraine headache $\ddagger$ & Migraine & Migraine without aura§ & Migraine with auraf \\
\hline \multicolumn{6}{|l|}{ Men } \\
\hline Died/total & $2433 / 7068$ & $457 / 1405$ & $175 / 571$ & $35 / 128$ & $140 / 443$ \\
\hline Age adjusted & 1.00 & 0.99 (0.90 to 1.09) & 0.99 (0.85 to 1.15$)$ & 0.81 (0.58 to 1.13$)$ & 1.05 (0.88 to 1.24$)$ \\
\hline Multivariable adjusted & 1.00 & 0.98 (0.89 to 1.09$)$ & 1.00 (0.86 to 1.17$)$ & $0.83(0.59$ to 1.16$)$ & $1.05(0.89$ to 1.25$)$ \\
\hline \multicolumn{6}{|l|}{ Women } \\
\hline Died/total & $1897 / 6003$ & $631 / 2226$ & $442 / 1452$ & $132 / 498$ & $310 / 954$ \\
\hline Age adjusted & 1.00 & 0.97 (0.88 to 1.06$)$ & 1.11 (1.00 to 1.23$)$ & 0.97 (0.81 to 1.16$)$ & $1.17(1.04 \text { to } 1.32)^{\star \star *}$ \\
\hline Multivariable adjusted & 1.00 & 0.99 (0.90 to 1.08$)$ & $1.14(1.02 \text { to } 1.26)^{\star \star}$ & 1.02 (0.86 to 1.22$)$ & $1.19(1.06 \text { to } 1.35)^{\star \star}$ \\
\hline \multicolumn{6}{|l|}{ Men and women } \\
\hline Died/total & $4330 / 13071$ & $1088 / 3631$ & $617 / 2023$ & $167 / 626$ & $450 / 1397$ \\
\hline Age-sex adjusted & 1.00 & 0.98 (0.91 to 1.05$)$ & 1.07 (0.98 to 1.17) & 0.93 (0.80 to 1.09) & $1.13(1.03 \text { to } 1.25)^{\star \star}$ \\
\hline Multivariable adjusted & 1.00 & $0.99(0.92$ to 1.05$)$ & $1.10(1.01 \text { to } 1.19)^{\star \star}$ & $0.97(0.83$ to 1.14$)$ & $1.15(1.04 \text { to } 1.27)^{\star \star}$ \\
\hline \multicolumn{6}{|c|}{$\begin{array}{l}\text { *Age, BMI, smoking (no, current, previous), education (primary, secondary, college/university), systolic and diastolic blood pressure, and use of } \\
\text { antihypertensive drugs. } \\
\text { †Of original } 18903 \text { participants, } 68(0.36 \%) \text { were lost to follow-up and } 110(0.58 \%) \text { had missing data on blood pressure, cholesterol concentration, } \\
\text { or BMI, leaving } n=18725 \text { with } 470990 \text { years of follow-up. } \\
\text { †Headache without or with one symptom of migraine once or more a month. } \\
\S 2-3 \text { of unilateral, photophobia, nausea symptoms. } \\
\text { †Migraine with visual or sensory symptoms, or both. Participants with symptoms of migraine without aura and migraine with aura were classified as } \\
\text { migraine with aura. } \\
\star \star \text { Significant at P<0.05. }\end{array}$} \\
\hline
\end{tabular}

into cancer and non-cancer and found that the risk was increased only for mortality other than cancer 1.33 , 1.13 to $1.57, \mathrm{P}=0.001$ ) (see appendix 2 on bmj.com).

Overall, using total mortality, our model suggests that at age 50 men and women with migraine with aura had a median loss of 1.5 and 1.4 years of life, respectively, compared with those without headache (see appendix 3 on bmj.com).

At age 50 the absolute risk of all cause mortality was low but still considerably higher for men than for women. For example, the 10 year risk for men aged 50 was $6.8 \%$ in those with no headache and $8.0 \%$ in those with migraine with aura; the corresponding values for women were $3.0 \%$ and $3.6 \%$. At age 70 the absolute 10 year risk had risen to $40.6 \%$ and $46.1 \%$ for men and 24.1\% and 27.9\% for women (see appendix 4 on bmj.com).

\section{DISCUSSION}

Principal findings

In this cohort study with over 470000 person years and a median follow-up of 26 years, men and women with migraine with aura were shown to be at increased risk of mortality from all causes and cardiovascular disease,

Table 5 |Risk of mortality from coronary heart disease according to migraine status in men and women in Reykjavik Study $\left(n=18725^{*}\right)$. Figures are age and multivariable $\nmid$ adjusted hazard ratios (95\% confidence intervals)

\begin{tabular}{|c|c|c|c|c|c|}
\hline & No headache & Non-migraine headache $\ddagger$ & Migraine & Migraine without aura§ & Migraine with auraף \\
\hline \multicolumn{6}{|l|}{ Men } \\
\hline Died/total & $1473 / 7068$ & $275 / 1405$ & $136 / 571$ & $26 / 128$ & $110 / 443$ \\
\hline Age adjusted & 1.00 & 0.99 (0.87 to 1.12$)$ & $1.29(1.08 \text { to } 1.54)^{\star \star}$ & 1.03 (0.70 to 1.52$)$ & $1.38(1.13 \text { to } 1.67)^{\star \star}$ \\
\hline Multivariable adjusted & 1.00 & 0.96 (0.85 to 1.10$)$ & $1.36(1.14 \text { to } 1.62)^{\star \star}$ & $1.12(0.76$ to 1.65$)$ & $1.43(1.18 \text { to } 1.74)^{\star \star}$ \\
\hline \multicolumn{6}{|l|}{ Women } \\
\hline Died/total & $590 / 6003$ & $213 / 2226$ & $123 / 1452$ & $35 / 498$ & $88 / 954$ \\
\hline Age adjusted & 1.00 & $1.13(0.96$ to 1.32$)$ & 1.13 (0.93 to 1.37$)$ & 0.98 (0.69 to 1.38$)$ & $1.20(0.96$ to 1.51$)$ \\
\hline Multivariable adjusted & 1.00 & $1.14(0.98$ to 1.34$)$ & $1.13(0.93$ to 1.37$)$ & $1.03(0.73$ to 1.46$)$ & 1.17 (0.93 to 1.47$)$ \\
\hline \multicolumn{6}{|l|}{ Men and women } \\
\hline Died/total & $2063 / 13071$ & $488 / 3631$ & $259 / 2023$ & $61 / 626$ & $198 / 1397$ \\
\hline Age-sex adjusted & 1.00 & $1.04(0.94$ to 1.14$)$ & $1.19(1.04 \text { to } 1.35)^{\star \star}$ & $0.97(0.75$ to 1.25$)$ & $1.28(1.10 \text { to } 1.48)^{\star \star}$ \\
\hline Multivariable adjusted & 1.00 & $1.03(0.94$ to 1.14$)$ & $1.22(1.07 \text { to } 1.39)^{\star \star}$ & $1.05(0.82$ to 1.37$)$ & $1.28(1.11 \text { to } 1.49)^{\star \star}$ \\
\hline \multicolumn{6}{|c|}{$\begin{array}{l}\text { * Of original } 18903 \text { participants, } 68(0.36 \%) \text { were lost to follow-up and } 110(0.58 \%) \text { had missing data on blood pressure, cholesterol concentration, } \\
\text { or BMI, leaving n=18 } 725 \text { with } 470990 \text { years of follow-up. } \\
\text { †Age, BMI, smoking (no, current, previous), education (primary, secondary, college/university), systolic and diastolic blood pressure, and use of } \\
\text { antihypertensive drugs. } \\
\text { †Headache without or with one symptom of migraine once or more a month. } \\
\S 2-3 \text { of unilateral, photophobia, nausea symptoms. } \\
\text { †Migraine with visual or sensory symptoms, or both. Participants with symptoms of migraine without aura and migraine with aura were classified as } \\
\text { migraine with aura. } \\
\star \star \text { Significant at } P<0.05 \text {. }\end{array}$} \\
\hline
\end{tabular}


Table $6 \mid$ Risk of mortality from stroke* according to migraine status in men and women in Reykjavik Study ( $\mathrm{n}=18 \mathrm{725} \dagger$ ). Figures are age and multivariableł adjusted hazard ratios ( $95 \%$ confidence intervals)

\begin{tabular}{|c|c|c|c|c|c|}
\hline & No headache & Non-migraine headache $\S$ & Migraine & Migraine without auraף & Migraine with aura** \\
\hline \multicolumn{6}{|l|}{ Men } \\
\hline Died/total & $373 / 7068$ & $63 / 1405$ & $37 / 571$ & $6 / 128$ & $31 / 443$ \\
\hline Age adjusted & 1.00 & $0.92(0.70$ to 1.20$)$ & 1.46 (1.04 to 2.05$) \dagger \dagger$ & 0.97 (0.43 to 2.18$)$ & $1.62(1.12$ to 2.34$) \dagger \dagger$ \\
\hline Multivariable adjusted & 1.00 & 0.90 (0.69 to 1.18$)$ & 1.55 (1.10 to 2.18$) \dagger †$ & $0.96(0.43$ to 2.15$)$ & $1.76(1.22$ to 2.54$) \dagger \dagger$ \\
\hline \multicolumn{6}{|l|}{ Women } \\
\hline Died/total & $292 / 6003$ & $99 / 2226$ & $63 / 1452$ & $18 / 498$ & $45 / 954$ \\
\hline Age adjusted & 1.00 & $1.08(0.86$ to 1.36$)$ & $1.20(0.91$ to 1.58$)$ & 1.05 (0.65 to 1.69$)$ & 1.27 (0.92 to 1.74$)$ \\
\hline Multivariable adjusted & 1.00 & $1.08(0.86$ to 1.36$)$ & 1.20 (0.91 to 1.59$)$ & 1.08 (0.67 to 1.75$)$ & $1.26(0.92$ to 1.73$)$ \\
\hline \multicolumn{6}{|l|}{ Men and women } \\
\hline Died/total & $665 / 13071$ & $162 / 3631$ & $100 / 2023$ & $24 / 626$ & $76 / 1397$ \\
\hline Age-sex adjusted & 1.00 & $1.01(0.85$ to 1.20$)$ & 1.27 (1.03 to 1.58$) \dagger \dagger$ & 1.01 (0.67 to 1.53$)$ & 1.38 (1.09 to 1.76$) \dagger \dagger$ \\
\hline Multivariable adjusted & 1.00 & 1.00 (0.84 to 1.19$)$ & 1.30 (1.05 to 1.61$) \dagger \dagger$ & $1.06(0.70$ to 1.60$)$ & $1.40(1.10$ to 1.78$) \dagger \dagger$ \\
\hline
\end{tabular}

*ICD-9 codes 431, 433, 434, 436, 438 and ICD-10 codes 161, 163, 164, 166, and I69.

†Of original 18903 participants, 68 (0.36\%) were lost to follow-up and $110(0.58 \%)$ had missing data on blood pressure, cholesterol concentration, or BMI, leaving $n=18725$ with 470990 years of follow-up.

$\ddagger$ Age, BMI, smoking (no, current, previous), education (primary, secondary, college/university), systolic and diastolic blood pressure, and use of antihypertensive drugs.

$\S$ Headache without or with one symptom of migraine once or more a month.

\2-3 of unilateral, photophobia, nausea symptoms.

** Migraine with visual or sensory symptoms, or both. Participants with symptoms of migraine without aura and migraine with aura were classified as migraine with aura.

††Significant at $\mathrm{P}<0.05$.

while those with migraine without aura were not at increased risk. Risk of mortality from cardiovascular disease was marginally more increased in men than in women with migraine and aura. Migraine with aura is an independent risk factor for cardiovascular and all cause mortality in men and women but weaker than major established risk factors, such as cigarette smoking, diabetes, and high blood pressure.

\section{Strengths and limitations}

This study had a large cohort, with a broad age range, long follow-up, and comprehensive data on conventional risk factors for cardiovascular disease at baseline as well as high ascertainment $(>99 \%)$ of cause specific mortality. The cohort is population based, which adds to the generalisability of our results. Although our classification of migraine precedes the 2004 IHS criteria, the questions are similar to those currently asked in the IHS criteria and cover the most common symptoms of migraine.

We did not ask about symptoms of migraine in those who reported having headache less than once a month and so are therefore likely to capture only those with higher attack frequency. People who had migraine

Table $7 \mid$ Risk of mortality from cardiovascular disease other than coronary heart disease and stroke according to migraine status in men and women in Reykjavik Study $\left(n=18725^{*}\right)$. Figures are age and multivariable $\nmid$ adjusted hazard ratios $(95 \%$ confidence intervals)

\begin{tabular}{|c|c|c|c|c|c|}
\hline & No headache & Non-migraine headache $†$ & Migraine & Migraine without auraf & Migraine with aura§ \\
\hline \multicolumn{6}{|l|}{ Men } \\
\hline Died/total & $240 / 7068$ & $50 / 1405$ & $16 / 571$ & $6 / 128$ & $10 / 443$ \\
\hline Age adjusted & 1.00 & $1.14(0.84$ to 1.54$)$ & 0.97 (0.58 to 1.60$)$ & 1.46 (0.65 to 3.29) & 0.80 (0.43 to 1.51$)$ \\
\hline Multivariable adjusted & 1.00 & 1.12 (0.83 to 1.53$)$ & 1.04 (0.63 to 1.73$)$ & 1.54 (0.68 to 3.47$)$ & 0.87 (0.46 to 1.64$)$ \\
\hline \multicolumn{6}{|l|}{ Women } \\
\hline Died/total & $179 / 6003$ & $65 / 2226$ & $36 / 1452$ & $13 / 498$ & $23 / 954$ \\
\hline Age adjusted & 1.00 & 1.19 (0.89 to 1.58$)$ & $1.16(0.81$ to 1.67$)$ & 1.29 (0.73 to 2.28$)$ & $1.10(0.71$ to 1.71$)$ \\
\hline Multivariable adjusted & 1.00 & 1.21 (0.91 to 1.61$)$ & $1.20(0.83$ to 1.72$)$ & $1.33(0.75$ to 2.35$)$ & $1.13(0.73$ to 1.76$)$ \\
\hline \multicolumn{6}{|l|}{ Men and women } \\
\hline Died/total & $419 / 13071$ & $115 / 3631$ & $52 / 2023$ & $19 / 626$ & $33 / 1397$ \\
\hline Age sex adjusted & 1.00 & 1.15 (0.93 to 1.42$)$ & $1.06(0.79$ to 1.42$)$ & 1.29 (0.81 to 2.05$)$ & 0.97 (0.68 to 1.38$)$ \\
\hline Multivariable adjusted & 1.00 & 1.15 (0.93 to 1.42$)$ & 1.12 (0.83 to 1.50$)$ & $1.39(0.87$ to 2.21$)$ & $1.00(0.70$ to 1.43$)$ \\
\hline
\end{tabular}

*Of original 18903 participants, 68 (0.36\%) were lost to follow-up and $110(0.58 \%)$ had missing data on blood pressure, cholesterol concentration, or BMI., leaving $n=18725$ with 470990 years of follow-up.

†Age, BMI, smoking (no, current, previous), education (primary, secondary, college/university), systolic and diastolic blood pressure, and use of antihypertensive drugs.

†Headache without or with one symptom of migraine once or more a month.

$\S 2-3$ of unilateral, photophobia, nausea symptoms.

IMigraine with visual or sensory symptoms, or both. Participants with symptoms of migraine without aura and migraine with aura were classified as migraine with aura. 
aura exclusively, without headache, would be included in the "no headache" group because of our screening question. We cannot draw any conclusions from the current study about the risk of mortality for people with migraine with low frequency of attacks (less than once a month) and those with migraine aura without headache.

The risk of cardiovascular outcomes might be higher in people with more frequent attacks of migraine. Kurth et al looked at frequency of attacks and risk of cardiovascular disease in a cohort of US women. ${ }^{24}$ They reported a J-shaped association between attack frequency and risk. If this J-shaped association applies to our current study, our estimates might be somewhat lower than we would have found if we had included everyone with migraine, although this is speculative.

The prevalence of aura (as a proportion of the total migraine population) is higher than has been reported in other population studies and might include commonly occurring non-specific visual symptoms such as blurring. The result of this misclassification would probably attenuate the relation between migraine with aura and mortality. We note that our prevalence of migraine overall (with and without aura combined), however, is highly consistent with previous studies. ${ }^{25}$

Finally, the combination of visual symptoms and headache can be symptoms of a transient ischaemic attack. If this were misclassified as migraine with aura in our study, it might exaggerate the association between migraine and mortality from cardiovascular disease. Our diagnosis of migraine, however, required headache at least once a month in the past 12 months, which is not a feature of transient ischaemic attack. Therefore we believe it is unlikely that this type of misclassification would have appreciably affected our results.

As we have data on vascular risk factors only at baseline, we did not adjust for potential changes in such risk factors that might have developed after the start of the study. These risk factors in adults tend to track over time $^{26}$ - that is, those at high risk tend to stay at high risk during follow-up and those at low risk tend to stay at low risk. While residual confounding because of imperfect control for vascular risk factors at baseline or after the start of the study is a possibility, we note that the hazard ratios scarcely changed after adjustment, arguing against a strong role for this sort of error.

Although about only $2 \%$ of affected people have new onset migraine over the age of $50,{ }^{27}$ the younger people in the cohort might have developed migraine after the study started and not been counted. We suggest that such a low percentage of people with migraine would be unlikely to change the risk estimates in the current study. Neither data on migraine specific treatment, such as ergotamine and triptans, nor data on the use of analgesics or steroid treatment were available. We could not therefore estimate the potential modifying effects of these drugs on the association between migraine and cardiovascular disease.
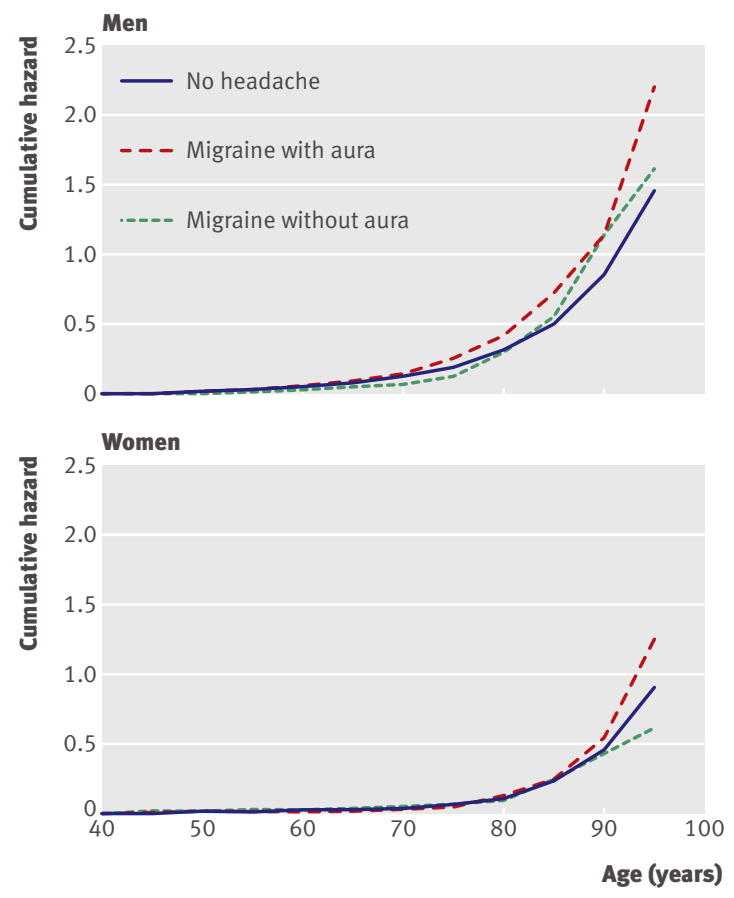

Migraine status and Nelson-Aalen cumulative hazards for mortality from cardiovascular disease. For men and women curve for non-migraine headache overlays curve for no headache and was therefore omitted

\section{Comparison with other studies}

This population based cohort study measured mortality from all causes and cardiovascular disease in men and women with migraine separately by aura status. Our findings are consistent with the increasing evidence that migraine, particularly migraine with aura, is associated with cardiovascular disease.$^{13428}$ Previous reports in which migraine has been shown to be protective for all cause mortality ${ }^{11} 1214$ could be explained by methodological differences with this study. For example, two of these studies ${ }^{1214}$ were based on patient based rather than population based samples. Furthermore, one of these studies ${ }^{14}$ identified those with migraine based in part on their use of triptans, which are contraindicated in people with risk factors for cardiovascular disease. The aim of the two studies ${ }^{12} 14$ was not to compare risk in those with and without migraine but to assess possible risk of triptans in people with migraine. The fact that those two studies showed a protective effect could also explain why a recent metaanalysis of five studies (including those two studies) showed no risk for mortality from cardiovascular disease associated with migraine overall (with and without aura combined) (relative risk $1.03,0.79$ to 1.34$).{ }^{6}$ Only one study included in that meta-analysis estimated the risk of mortality separately in people with migraine with aura. ${ }^{4}$ This study suggested that women with migraine with aura were at about twice the risk of cardiovascular mortality compared with women without headache.

The hazard ratios for mortality for cardiovascular disease in men with migraine were somewhat higher than the corresponding values for all cause mortality. 


\section{WHAT IS ALREADY KNOWN ON THE TOPIC}

Individuals with migraine with aura (but not without aura) are at almost twice the risk of ischaemic stroke than other people

Individuals with migraine (with and without aura combined) are not at increased risk of death from cardiovascular disease

Compared with women without headache, women with migraine with aura (but not without aura) are at increased risk of death from cardiovascular disease after age 45

\section{WHAT THIS STUDY ADDS}

Migraine with aura is an independent risk factor for cardiovascular and all cause mortality in both men and women but is weaker than major established risk factors, such as smoking, diabetes, and high blood pressure

Women with migraine with aura were at increased risk of mortality from non-cardiovascular disease

People with migraine, particularly those with aura, were at increased risk of death from coronary heart disease and stroke
The risk was independent of traditional risk factors for cardiovascular disease measured at baseline. Several studies have reported greater risk of stroke in people with migraine ${ }^{1628}$ than in others, especially for those with aura. ${ }^{14628}$ The risk of coronary heart disease among people with migraine varies more between studies, from being lower than normal to being moderately increased. ${ }^{6}$ In our study the risk increase for mortality from coronary heart disease was mainly confined to men with migraine with aura.

The increased risk of overall mortality or mortality related to cardiovascular disease associated with migraine with aura is significant but modest: $20 \%$ for women and $20 \%$ for men, with respect to all cause mortality, and $18 \%$ for women and $42 \%$ for men, with respect to cardiovascular disease mortality.

We estimated that at age 50 men and women with migraine with aura had a median loss of 1.5 or 1.4 years of life compared with those without headache. By way of comparison with more established risk factors for all cause mortality, the median loss of life in the Reykjavik Study for those with untreated high blood pressure $(\geq 160 \mathrm{~mm} \mathrm{Hg}$ ), type 2 diabetes, and smoking 15 cigarettes or more a day was, respectively, about 5,5 , and 13 years for men and 3,3 , and 9 years for women ${ }^{2930}$ (see appendix 3 on bmj.com).

In people with migraine with aura, compared with those without headache, the excess absolute 10 year risk of all cause mortality at age 50 was low: $1.2 \%$ for men $(8.0 \% v 6.8 \%$ risk of all cause mortality) and $0.6 \%$ for women $(3.6 \% v 3.0 \%)$. At age 70, the excess absolute risk of all cause mortality in people with migraine with aura was higher, at $5.5 \%$ for men $(46.1 \% v 40.6 \%)$ and $3.8 \%$ for women $(27.9 \% v 24.1 \%)$.

\section{Potential mechanisms}

Several mechanisms could explain the link between migraine and cardiovascular disease, though none has been definitively established. Migraine and ischaemic events have been linked through a genetic component. ${ }^{31}$ They might reflect associations between migraine with aura and vasculopathy ${ }^{32}$ and mitochondrial myopathy, encephalopathy, lactic acidosis, and stroke (MELAS). ${ }^{33}$ Methylenetetrahydrofolate reductase (MTHFR) is an important enzyme in the metabolism of homocysteine, derived from the amino acid methionine, and a risk factor for cerebral small vessel disease $^{34}$ and migraine. ${ }^{35}$ Migraine could directly cause an ischaemic event that is from a migrainous infarct, but such events are rare, about $3 \%$ of all strokes, ${ }^{36}$ and can therefore account for only a small proportion of all strokes in people with migraine. There is increasing evidence that migraine is associated with coronary heart disease, ${ }^{437}$ and one study reported an association between migraine and an increased prevalence of conventional vascular risk factors. ${ }^{9}$ The current data show little difference in risk factors between those with and without migraine, which is in line with previous studies on people with migraine in the Reykjavik Study. ${ }^{78}$ Our results were similar with and without adjustment for conventional risk factors for cardiovascular disease, suggesting that the mechanism(s) linking migraine to cardiovascular disease are from a different pathway. Others have reported that people with migraine, even in the absence of conventional risk factors, are at increased risk of stroke ${ }^{37}$ and have decreased cerebral and peripheral vascular resistance, retinal microvascular signs, hypercoagulability, and inflammation, ${ }^{3138}$ supporting the hypothesis that migraine might be a systemic disorder that is affecting vasculature. ${ }^{39}$ People with migraine have been shown to have altered vascular reactivity at a young age (under 25 years) ${ }^{40}$ which indicates that there might be a factor affecting both the onset of migraine and progression of cardiovascular disease early in life. A recent study reported that people with migraine without aura had reduced function and number of endothelial progenitor cells, ${ }^{38}$ which has been associated with higher Framingham risk scores in people with coronary heart disease ${ }^{41}$ and increased risk of mortality from cardiovascular disease. $^{42}$

\section{Implications}

People with migraine, particularly those with migraine with aura, are at a modestly increased risk of mortality, independent of classic risk factors for cardiovascular disease measured in mid-life. The absolute risk is low, and the focus should be on conventional risk factors, such as hypertension, smoking, and adverse lipid profile, for reducing the risk of cardiovascular disease, regardless of migraine status.

\section{Future research}

More research is needed on the association between migraine and mortality from cardiovascular disease, non-cardiovascular disease, and all causes, including studies to identify whether there are specific subgroups of people with migraine who are at particular risk because of genetic or environmental factors. Future studies should assess aura status and frequency of attacks in detail, and prospective studies can monitor changes in the risk profile for cardiovascular disease 
over time to better understand the aetiology and pathophysiology of migraine in its development. Finally, studies are needed to determine if reducing the frequency of attacks with migraine preventive treatment might reduce the risk of cardiovascular disease.

We thank all the employees of the Icelandic Heart Preventive Clinic (Hiartavernd) for their skilful contribution to the data collection. Contributors: LSG, AIS, LL, and VG designed the study. LSG and TA analysed the data. LSG and VG drafted the paper. TA and VG acquired the data. LSG and TA take responsibility for the integrity of the data and the accuracy of the data analysis. All authors had access to the data, interpreted the data, critically revised the draft for important intellectua content, and gave final approval of the manuscript to be published. LSG and VG are guarantors.

Funding: This study was funded by the University of Iceland Research Fund. The current study was conducted without any influence from the University of Iceland Research Fund.

Competing interests: All authors have completed the Unified Competing Interest form at www.icmje.org/coi_disclosure.pdf (available on request from the corresponding author) and declare that no company has supported the submitted work; LSG has received a travel grant from the Pharmaceutical Society of Iceland Science Fund, AIS has served on advisory boards for Endo Pharmaceuticals and OrthoMcNeil Neurologics, has received an honorarium and a travel grant from the National Headache Foundation and a travel grant from the American Headache Society; no other relationships or activities that could appear to have influenced the submitted work

Ethical approval: This study was approved by the Surgeon General's ethics committee 1969, and informed consent was given by all participants.

Data sharing: No additional data are available.

1 Bousser MG, Welch KM. Relation between migraine and stroke. Lancet Neurol 2005;4:533-42.

2 Kruit MC, van Buchem MA, Hofman PA, Bakkers JT, Terwindt GM, Ferrari MD, et al. Migraine as a risk factor for subclinical brain lesions. JAMA 2004;291:427-34.

3 Kurth T, Gaziano JM, Cook NR, Bubes V, Logroscino G, Diener HC, et al. Migraine and risk of cardiovascular disease in men. Arch Intern Med 2007;167:795-801.

4 Kurth T, Gaziano JM, Cook NR, Logroscino G, Diener HC, Buring JE. Migraine and risk of cardiovascular disease in women. JAMA 2006;296:283-91.

5 Scher Al, Gudmundsson LS, Sigurdsson S, Ghambaryan A Aspelund T, Eiriksdottir G, et al. Migraine headache in middle age and late-life brain infarcts. JAMA 2009;301:2563-70.

6 Schurks M, Rist PM, Bigal ME, Buring JE, Lipton RB, Kurth T. Migraine and cardiovascular disease: systematic review and meta-analysis. BMJ 2009;339:b3914.

7 Gudmundsson LS, Aspelund T, Scher Al, Thorgeirsson G, Johannsson M, Launer LJ, et al. C-reactive protein in migraine sufferers similar to that of non-migraineurs: the Reykjavik Study. Cephalalgia 2009;29:1301-10.

8 Gudmundsson LS, Thorgeirsson G, Sigfusson N, Sigvaldason H, Johannsson M. Migraine patients have lower systolic but highe diastolic blood pressure compared with controls in a populationbased study of 21,537 subjects. The Reykjavik Study. Cephalalgia 2006;26:436-44.

9 Scher Al, Terwindt GM, Picavet HS, Verschuren WM, Ferrari MD, Launer LJ. Cardiovascular risk factors and migraine: the GEM population-based study. Neurology 2005;64:614-20.

10 Kurth T, Ridker PM, Buring JE. Migraine and biomarkers of cardiovascular disease in women. Cephalalgia 2008;28:49-56

11 Waters WE, Campbell MJ, Elwood PC. Migraine, headache, and survival in women. BMJ 1983;287:1442-3.

12 Hall GC, Brown MM, Mo J, MacRae KD. Triptans in migraine: the risks of stroke, cardiovascular disease, and death in practice. Neurology 2004;62:563-8.

13 Liew G, Wang J,, Mitchell P. Migraine and coronary heart disease mortality: a prospective cohort study. Cephalalgia 2007;27:368-71.

14 Velentgas P, Cole JA, Mo J, Sikes CR, Walker AM. Severe vascular events in migraine patients. Headache 2004:44:642-51.

15 Jonsdottir LS, Sigfusson N, Gudnason V, Sigvaldason H, Thorgeirsson G. Do lipids, blood pressure, diabetes, and smoking confer equal risk of myocardial infarction in women as in men? The Reykjavik Study. J Cardiovasc Risk 2002;9:67-76.
16 Sigurdsson E, Thorgeirsson G, Sigvaldason H, Sigfusson N. Unrecognized myocardial infarction: epidemiology, clinical characteristics, and the prognostic role of angina pectoris. The Reykjavik Study. Ann Intern Med 1995;122:96-102.

17 Headache Classification Subcommittee of the International Headache Society. The international classification of headache disorders. 2nd ed. Cephalalgia 2004;24(suppl 1):9-160S.

18 Conroy RM, Pyorala K, Fitzgerald AP, Sans S, Menotti A, De Backer G, et al. Estimation of ten-year risk of fatal cardiovascular disease in Europe: the SCORE project. Eur Heart J 2003;24:987-1003.

19 Tunstall-Pedoe H, Kuulasmaa K, Amouyel P, Arveiler D, Rajakangas AM, Pajak A. Myocardial infarction and coronary deaths in the World Health Organization MONICA project. Registration procedures, event rates, and case-fatality rates in 38 populations from 21 countries in four continents. Circulation 1994;90:583-612.

20 Grambsch PM, Therneau TM. Proportional hazards tests and diagnostics based on weighted residuals. Biometrika 1994;81:515-26.

21 Schoenfeld D. Partial residuals for the proportional hazards regression model. Biometrika 1982;69:239-41.

22 Aalen 00. Non parametric inference for a family of counting processes. Ann Stat 1978;6:701-26.

23 Nelson W. Theory and applications of hazard plotting for censored failure data. Technometrics 1972;14:945-66

24 Kurth T, Schurks M, Logroscino G, Buring JE. Migraine frequency and risk of cardiovascular disease in women. Neurology 2009;73:581-8.

25 Stovner L, Hagen K, Jensen R, Katsarava Z, Lipton R, Scher A, et al. The global burden of headache: a documentation of headache prevalence and disability worldwide. Cephalalgia 2007;27:193-210.

26 Ulmer H, Kelleher C, Diem G, Concin H. Long-term tracking of cardiovascular risk factors among men and women in a large population-based health system: the Vorarlberg Health Monitoring and Promotion Programme. Eur Heart J 2003;24:1004-13.

27 Bigal ME, Liberman JN, Lipton RB. Age-dependent prevalence and clinical features of migraine. Neurology 2006;67:246-51.

28 Bigal ME, Kurth T, Santanello N, Buse D, Golden W, Robbins M, et al. Migraine and cardiovascular disease. A population-based study. Neurology 2010;74:628-35.

29 Olafsdottir E, Aspelund T, Sigurdsson G, Thorsson B, Benediktsson R, Harris T, et al. [Life expectancy of subjects with type two diabetes compared to others 1967-2007.] Abstract. Laeknabladid 2009;58:65.

30 Sigfusson N, Sigurdsson G, Aspelund T, Gudnason V. [The health risk associated with smoking has been seriously underestimated. The Reykjavik Study.] Laeknabladid 2006;92:263-9.

31 Del Zotto E, Pezzini A, Giossi A, Volonghi I, Padovani A. Migraine and ischemic stroke: a debated question. J Cerebr Blood FMet 2008;28:1399-421.

32 Vahedi K, Chabriat H, Levy C, Joutel A, Tournier-Lasserve E, Bousser MG. Migraine with aura and brain magnetic resonance imaging abnormalities in patients with CADASIL. Arch Neurol 2004;61:1237-40

33 Pavlakis SG, Phillips PC, DiMauro S, De Vivo DC, Rowland LP. Mitochondrial myopathy, encephalopathy, lactic acidosis, and strokelike episodes: a distinctive clinical syndrome. Ann Neurol 1984; $16: 481-8$

34 Hassan A, Hunt BJ, O’Sullivan M, Bell R, D’Souza R, Jeffery S, et al. Homocysteine is a risk factor for cerebral small vessel disease, acting via endothelial dysfunction. Brain 2004;127:212-9.

35 Scher Al, Terwindt GM, Verschuren WM, Kruit MC, Blom HJ, Kowa H, et al. Migraine and MTHFR C677T genotype in a population-based sample. Ann Neurol 2006;59:372-5.

36 Henrich JB, Sandercock PA, Warlow CP, Jones LN. Stroke and migraine in the Oxfordshire community stroke project. / Neurol 1986;233:257-62

37 Kurth T, Schurks M, Logroscino G, Gaziano JM, Buring JE. Migraine, vascular risk, and cardiovascular events in women: prospective cohort study. BMJ 2008;337:a636.

38 Lee ST, Chu K, Jung KH, Kim DH, Kim EH, Choe VN, et al. Decreased number and function of endothelial progenitor cells in patients with migraine. Neurology 2008;70:1510-7.

39 Tietjen GE. Migraine as a systemic vasculopathy. Cephalalgia 2009;29:987-96.

40 Vanmolkot FH, Van Bortel LM, de Hoon JN. Altered arterial function in migraine of recent onset. Neurology 2007;68:1563-70.

41 Hill JM, Zalos G, Halcox JP, Schenke WH, Waclawiw MA, Quyyumi AA, et al. Circulating endothelial progenitor cells, vascular function, and cardiovascular risk. N Engl J Med 2003;348:593-600.

42 Werner N, Kosiol S, Schiegl T, Ahlers P, Walenta K, Link A, et al. Circulating endothelial progenitor cells and cardiovascular outcomes. N Engl J Med 2005;353:999-1007.

Accepted: 12 July 2010 